\title{
Urban Freshwater Needs and Spatial Cost Externalities for Coastal Aquifers: A Theoretical Approach
}

\author{
Michel Moreaux* and Arnaud Reynaud ${ }^{\dagger}$
}

8th December 2003

\begin{abstract}
Saltwater intrusion in coastal aquifers is one of the main causes of groundwater quality degradation. These intrusions are often due to excessive withdrawals in sensible parts of coastal aquifers. The scope of this paper is to identify specific problems set by optimal management of such a resource. To this end, we develop a simple spatial model describing a coastal aquifer under seawater intrusion. We show that water mining creates a specific cost externality between population spread over the aquifer. We then characterize the system of taxes that must be used to implement the optimum in a decentralized economy.
\end{abstract}

Keywords : Natural resource, Urban water needs, Spatial model, Groundwater, Water pricing. JEL Codes : R12, Q25, L95.

\footnotetext{
${ }^{*}$ Université de Toulouse I (IUF, LEEERNA-INRA and IDEI, 21 allée de Brienne, 31000 Toulouse, France.

${ }^{\dagger}$ LEEERNA-INRA, Université de Toulouse I, 21 allée de Brienne, 31000 Toulouse, France. Tel: (33)-5-61-12-88-76. Fax: (33)-5-61-12-85-20. Email: areynaud@toulouse.inra.fr. Corresponding author.
} 


\section{Introduction}

According to the Food and Agriculture Organization ${ }^{1}$, six out of ten people live within sixty kilometers of a coast and more than two thirds of the population of developing countries live in the vicinity of the sea. For most of this urban population, groundwater is often the main source of freshwater. Groundwater systems have also become during the last decades an important source of fresh water throughout the world. They provide now about one-third of the world freshwater consumption according to Gleick (1993). The increased pressure on groundwater has often resulted in an important fall in aquifer levels. ${ }^{2}$ In coastal aquifers where freshwater is connected to seawater, high withdrawals can endanger the long-term use of the resource. Under natural equilibrium conditions the hydraulic gradient ensures a water run-off toward the sea protecting freshwater. But the gradient is often relatively small and any excessive net withdrawal alters the hydrostatic balance. Then seawater enters more deeply into the aquifer and replaces freshwater. This phenomenon, known as seawater intrusion, prohibits access to the resource for the users in the coastal areas. This problem of seawater intrusion has widely been recognized in groundwater utilization for many coastal aquifers in various parts of the world. Given the geographical repartition of needs, it is now one of the main causes of groundwater quality degradation and one of the major constraint affecting groundwater management, according to Bear et al. (1999).

Although seawater intrusion is a critical problem for many coastal aquifers, it is very surprising to notice that only few economic literature has addressed this issue. ${ }^{3}$ Moreover, most of the economic literature has focused on the dynamic problems created by seawater intrusion, see Moreaux and Reynaud (2004) for a recent survey. For example, Tsur and Zemel (1995) simply consider saline intrusion

\footnotetext{
${ }^{1}$ See for instance the technical report F.A.0 (1997).

${ }^{2}$ Currently, about one-fourth of the groundwater withdrawn in the US is not replenished. At the current rate of extraction, Saudi Arabic's nonrenewable fossil groundwater will be exhausted within twenty years.

${ }^{3}$ Sea water intrusion in coastal aquifers is on contrary a very active field of research in hydrogeology. Two international conferences are organized every two years: the SWIM meeting (since 1968) and the SWICA-M3 conference (since 2001). A brief look to the SALNET bibliography dedicated to seawater intrusion shows that 448 papers related to this topic have been published in scientific journals. Considering only sea water intrusion along the Atlantic Coast of the United States, the US Geological survey bibliography contains 549 references (book, article, technical report, map).
} 
as an irreversible event occurring when the groundwater table declines below some unknown threshold level. In Koundouri (1997) the aquifer is modeled as a "bathtub" in which water quality goes progressively worth due to seawater intrusion. The only work having explicitly integrated the spatial aspect of seawater intrusion is Cummings (1971). However as the economical framework is not directly set on a truly validated hydrological model, it makes the policy implications difficult to derive.

In this paper, we develop a spatial model for managing coastal aquifers under seawater intrusion conditions. Populations are spread over the aquifer according to a given discrete distribution. Distribution mass points correspond to cities that are going to compete for groundwater extraction. For each city, both the rate of withdrawal and the pumping location are endogeneous decisions. The longrun optimal water allocation between cities is then characterized and economic instruments aiming at implementing this optimum are identified. We especially focus on the type of externalities created by water pumpings. First, water withdrawals create a pumping cost externality because the water table decreases with total pumping. Second, water withdrawals create a transportation cost externality. The higher are total withdrawals, the more landward the hydraulic interface is located and the higher are the water supply costs of users located in the coastal area. It follows that users far away from the coast create a negative externality on users located nearer. How is it possible to internalize this externality? Is a single price for all users sufficient to implement an optimal allocation of water? Do we need a spatially differenciated price system? This is the kind of question we try to answer in this paper, assuming that the objective of the social planner is to maximize the net social surplus.

The paper is organized as follows. Section 2 describes the model. Some generic characteristics of the problem are already visible while the coastal aquifer is exploited by a single city. In particular, the optimal exploitation by a single user-group (section 3) allows to highlight some problems created by the discontinuity of the water supply marginal cost. It is however obvious that the cost externalities created by different pumpings may only be analyzed in a model with at least two user-groups. Section 
4 presents a complete analysis of the two user-groups case. We conclude by summarizing our findings.

\section{A spatial model of coastal aquifer under seawater intrusion}

\subsection{A two-dimensional sharp interface model}

\subsubsection{Aquifer structure}

A coastal aquifer is recharged by fresh water entering at the landward boundary, at a distance $X_{0}$ to the coast. $R$ denotes the constant instantaneous recharge rate, i.e., the net water inflow excluding extraction. At the sea water boundary, there is an influx of sea water which migrates to the bottom of the aquifer and displaces the fresh water upward because of greater density. We note $H_{0}$ the depth of the aquifer measured from the sea level. Figure 1 describes this standard two-dimensional model of coastal aquifer under saline intrusion conditions.

[Figure 1, here]

Under natural equilibrium conditions, fresh water denser than salt water forms a lens that floats on salt water. This lens is moved by a permanent flow discharging into the sea. Where fresh water and sea water come into contact, mechanical dispersion causes mixing and a transition zone forms. As a simplification, we neglect this brackish zone and assume that the interface is sharp. ${ }^{4}$ Let us denote by $x$, the distance from an inland point on aquifer to the coast, by $h(x)$ the height of the water table measured from the sea level, by $H(x)$ the depth below sea level to a point on the interface and by $L$ the maximal intrusion of sea water. Under natural equilibrium conditions, i.e. without any water

\footnotetext{
${ }^{4}$ The passage from the portion of the aquifer that is occupied by sea water to that occupied by fresh water takes the form of a transition zone. Depending upon aquifer properties, this zone can small relative to the aquifer's thickness and it can be approximated as a sharp interface.
} 
extraction, $h(x), H(x)$ are given by :

$$
\begin{aligned}
& h(x)= \begin{cases}\left(\frac{2}{k} \frac{a^{2}}{1+a} R x\right)^{\frac{1}{2}} & \text { if } x \leq L \\
{\left[\left((1+a)^{2}+\frac{2 R}{k H_{0}^{2}}(x+L)\right)^{\frac{1}{2}}\right] H_{0}-H_{0}} & \text { if } L<x\end{cases} \\
& H(x)= \begin{cases}\left(\frac{2}{k} \frac{1}{1+a} R x\right)^{\frac{1}{2}} & \text { if } x \leq L \\
H_{0} & \text { if } L<x\end{cases}
\end{aligned}
$$

where $k$ is the hydraulic conductivity of the aquifer (distance unit/time unit) and $a$ is the density differential ratio between salt water and fresh water to fresh water density. ${ }^{5}$ The maximum length of sea water intrusion at the bottom of the aquifer, $L$, is given by:

$$
L=(1+a) H_{0}^{2} k / 2 R
$$

The system (1)-(3) provides the fundamental relationship between the rate of fresh water recharge and the length of the intruding sea water wedge at the static equilibrium. The interested reader may consult Bear et al. (1999) for a more formal derivation of these equations. It is worth noticing that this type of model has been recently used by hydrogeologists for analyzing real cases. For US, Bear et al. (1999) report for instance that a sharp-interface model at the static equilibrium has been used in the mid eighties for the Cape Code aquifer (Massachusetts) and for the Montauk peninsula aquifer (Long Island, New York). More recently, the model of the Soquel-Aptos Basin aquifer (California) was also designed along the same lines.

When pumping occurs, only a part of the fresh water recharge is discharged to the sea. This determines a new hydrostatic equilibrium between fresh water and salt water. As water extraction rate increases, the interface moves landward and upward. Salt water moves to the bottom of the aquifer and displaces the fresh water landward and the water table decreases. The fresh water lens goes thinner. As salt water intrusion progresses, pumping wells close to the coast become saline and

\footnotetext{
${ }^{5}$ This hydrological model requires the following assumptions to hold: homogeneity (the physical structure of the system is the same in the whole aquifer), perfect hydraulic conductivity (any action that affects a part of aquifer has an impact on the whole aquifer), closeness (the system considered is closed), hydrostatic approximation for sea water (sea water is static), quasi-hydrostatic approximation for fresh water (the fresh water flow is horizontal).
} 
have to be abandoned. ${ }^{6}$ Let us denote by $Y, Y<R$, the total water extraction rate so that the net recharge of fresh water is $R-Y$. The aquifer structure with pumping is given by substituting $R-Y$ for $R$ in equations (1)-(3). ${ }^{7}$ We denote by $h(x, Y), H(x, Y)$ and $L(Y)$ the aquifer characteristics when water pumping rate is equal to $Y$. This long-term equilibrium model differs from previous dynamic works like Cummings (1971) or Green and Sunding (2000) in a crucial way. In these papers seawater intrusion is viewed as a type of pollution that degrades the quality of the resource by increasing salinity. By pumping groundwater, the hydraulic head is reduced and seawater intrudes the aquifer. One of the key points of these papers is that the effect of pumping on seawater intrusion depends on the location of pumping, the idea being that pumping groundwater closer to the coast causes more intrusion than pumping further inland. Here, any pumping has the same effect on seawater intrusion whatever is its location on the aquifer. This is a direct consequence of the perfect hydraulic conductivity assumption of the hydrological model which holds as we only consider the long-term static equilibrium and we do not analyze transitory regimes of the system.

\subsubsection{Pumping constraints induced by sea water intrusion}

By increasing water withdrawals, salt water moves upward. Well discharge near the coast becomes saline to a degree governed by location of the wells, discharge rates and hydrologic conditions. Such a kind of discharge can obviously not be considered as a long-run extraction plan. Thus wells located in

\footnotetext{
${ }^{6}$ Drinking water standards established by the E.P.A require drinking water to contain no more than $0.5 \mathrm{~g} / \mathrm{L}$ of TSS, a common measure of salinity. Sea water contains approximately $30 \mathrm{~g} / \mathrm{L}$ of TSS. According to the F.A.O standard, a two to three percent mixing with sea water renders fresh water inadequate for human consumption and for irrigation. A four percent mixing is enough to destroy at least partially a fresh water resource. This problem could be solved by desalting water, as it is done along the coast of some arid countries (Israel, Kuwait, Saudi Arabia among others). However, the desalting processes remains often too costly to be used extensively. Salinity can also be detrimental to agriculture by reducing yields and killing crops with low tolerance to salt. In some cases, conditions may necessitate a change to crops that are more salt tolerant. For cooling purposes, salt water and brackish water are neither attractive. Saltwater may cause damages to the installations by corrosion and it produces brine as a by-product which is costly to dispose of or to transport.

${ }^{7}$ We know however that water table depends also on geographical withdrawals repartition. If there is a finite number of pumping points exploiting aquifer, the hydraulic head is distorded around each of these points: this phenomenom is known as upconing. Under some conditions, saltwater moves upward in response to pumping and the well discharge becomes saline to a degree governed by location of the wells, discharge rates and local hydrologic conditions. See Reilly and Goodman (1985) and Reilly and Goodman (1988) for a fairly complete description of the upconing problem.
} 
coastal areas have to be excluded from the water supply system because they cannot ensure potable water. Therefore, the greater total water extraction, the more the frontier of feasible wells moves landward. In order to take into account this spatial constraint while keeping the model tractable, we assume that water pumping must occur at some critical distance of water table and at some critical distance of the interface. At any point $x$ of the aquifer, pumping depth must be between $h(x)-d_{h}$, $d_{h}>0$ and $-H(x)+d_{H}, d_{H}>0$. In other words, pumping water at a location $x$ is feasible only if the thickness of the freshwater lens is greater than $d_{h}+d_{H}$. The major assumption is that the security distances, $d_{h}$ and $d_{H}$, do not depend upon wells locations and discharges. These security distances define first a minimal distance to the coast beyond which any pumping well must be located. This distance is a function of total water extraction $Y$ and is denoted by $\bar{x}(Y)$. By definition, $\bar{x}(Y)$ is solution of $h(x, Y)-d_{h}=-H(x, Y)+d_{H}$, that is:

$$
\bar{x}(Y)=\frac{k\left(d_{h}+d_{H}\right)^{2}}{2(R-Y)(1+a)} .
$$

It can easily be shown that $\bar{x}(Y)$ is increasing and convex. Moreover, for a given withdrawal rate, the minimal distance to the coast increases with the security distances $d_{h}$ and $d_{H}$. The minimal distance function is defined on $\left[0, \bar{Y}^{0}\right]$, with $\bar{Y}^{0}<R$ corresponding to the maximum feasible pumping rate available at the landward bound of the aquifer, solution of $\bar{x}(Y)=X^{0}$. We denote by $\underline{x}$ the minimal distance to the coast where fresh water is available when there is no pumping elsewhere. The security constraints can also be defined as $\bar{Y}(x)$, the maximal feasible pumping rate $\bar{Y}$ as a function of the location $x$. In case of a single well extracting water from the aquifer at a distance $x$ to the coast, $\bar{Y}(x)$ gives the maximal pumping rate satisfying the security constraints at this point:

$$
\bar{Y}(x)= \begin{cases}0 & \text { if } x \leq \underline{x} \\ R-\frac{1}{x} \frac{k\left(d_{h}+d_{H}\right)^{2}}{2(1+a)} & \text { if } x>\underline{x} .\end{cases}
$$

For $x$ smaller than $\underline{x}$, no water is available and the maximal pumping rate at $x$ is zero. For $x$ greater than $\underline{x}, \bar{Y}$ is the inverse function $\bar{x}^{-1}$. Let us finally notice one interesting property of the function 
$\bar{Y}(x)$. We have $\forall x \in\left[\underline{x}, X^{0}\right]$ :

$$
h[x, \bar{Y}(x)]=\frac{a}{1+a}\left(d_{h}+d_{H}\right) \equiv \underline{h} \quad \text { and } \quad H[x, \bar{Y}(x)]=\frac{1}{1+a}\left(d_{h}+d_{H}\right) \equiv \bar{H}
$$

The water table elevation and the interface position corresponding to the maximum feasible pumping rate do not depend on the location of the pumping point. This physical property clearly results from the fact that the security distances, $d_{h}$ and $d_{H}$, do not depend upon wells locations and discharges.

If there are other pumping wells located upward with an aggregate pumping rate $Y, Y<\bar{Y}(x)$, then the maximal pumping rate at $x$ is given by:

$$
\max \{\bar{Y}(x)-Y, 0\}
$$

This spatial constraint is similar to that faced by users located along a canal which presents losses, problem studied by Chakravorty, Hochman, and Zilberman (1995). The quantity of resource available at a point of the canal is equal to the flow available upward less the network losses between these two points. Brozovic, Sunding, and Zilberman (2001) propose a similar analysis in the case of groundwater.

\subsection{Economic modeling}

The coastal aquifer is exploited by $I$ cities indexed by $i, i=1, \ldots, I . x_{i}^{0}$ denotes the distance from city $i$ to the coast. As a convention, cities are indexed by increasing distance to the coast: $x_{1}^{0}<\ldots<x_{i}^{0}<$ $\ldots<x_{I}^{0}$. We suppose that city $i$ is made of $n_{i}$ identical representative individuals having the same activities, the same tastes and the same incomes. Thus optimal consumption per capita is identical for all users living in the same city. We denote by $y_{i}$ the instantaneous water consumption per capita of the city $i$, by $Y_{i}=n_{i} y_{i}$ the total consumption of city $i$ and by $Y=\sum_{i} Y_{i}$ the total water extraction of all cities exploiting the coastal aquifer. ${ }^{8}$ The individual utility function only depends on water consumption and is assumed to be the same for all representative consumers. The utility function

\footnotetext{
${ }^{8}$ As a simplification, we do not distinguish between net and gross withdrawals. We assume that water pumping if definitively lost for the groundwater system.
} 
is denoted by $U($.$) . We make the following standard assumptions: U$ is supposed twice continuously differentiable, strictly increasing and concave and water is considered as an essential good so that the Inada condition holds:

$$
\frac{d U}{d y}>0, \quad \frac{d^{2} U}{d y^{2}}<0, \quad \text { and } \quad \lim _{y \rightarrow 0} \frac{d U}{d y}=+\infty
$$

Finally, $V_{i}$ denotes the aggregate utility function for city $i$ : $V_{i}\left(Y_{i}\right)=n_{i} U\left(Y_{i} / n_{i}\right)$. By construction, $V_{i}$ is strictly increasing and concave.

Total water supplying costs are constituted by pumping costs and surface conveyance costs. We denote $\alpha, \alpha>0$, the unit cost of pumping per unit of discharge and elevation. Defining pumping costs requires to characterize the ground level. We assume that ground elevation, measured from the sea level, is characterized by a function $g(x)>0$ for $x \in\left[0, X^{0}\right]$. Different ground profiles may be considered. Here, we assume :

$$
\frac{d g}{d x}>0 \text { and } \frac{d}{d x}[g(x)-h(x)]>0 \quad \forall x
$$

The first assumption means that the ground elevation increases with the distance to the coast. The second assumption means that, for any given level of water withdrawals, the depth at which fresh water is accessible increases with the distance to the coast. This corresponds to the fact that access to groundwater is usually easier in coastal areas where fresh water is discharged into the sea than in more inland areas. ${ }^{9}$ An immediate implication of the second above inequality (9) is that:

$$
\frac{d}{d x}[g(x)-h(x, Y)]>0 \quad \forall x, Y
$$

The total cost of pumping $Y_{i}$ from the location $x_{i}$ when total pumping elsewhere is $Y_{-i}$ is: $\alpha \cdot\left[g\left(x_{i}\right)-\right.$ $\left.h\left(x_{i}, Y_{i}+Y_{-i}\right)\right] \cdot Y_{i}$. The surface water conveyance cost from the pumping point to city $i$ location is proportional to the distance and the discharge. We note $\beta, \beta>0$ the unit conveyance cost per unit of distance and discharge. Thus the conveyance cost of city $i$ pumping $Y_{i}$ from a well located in $x_{i}$ is:

\footnotetext{
${ }^{9}$ Some other assumptions for the ground profile may also be considered as realistic. In particular, the ground elevation may in some cases not increase monotonically with the distance to the coast. We let this case for future research.
} 
$\beta \cdot\left|x_{i}-x_{i}^{0}\right| \cdot Y_{i}$. The total water supplying cost of city $i$ pumping $Y_{i}$ at $x_{i}$, denoted $T C_{i}\left(Y_{i}, Y_{-i}, x_{i}\right)$, is finally:

$$
T C_{i}\left(Y_{i}, Y_{-i}, x_{i}\right)=\alpha \cdot\left[g\left(x_{i}\right)-h\left(x_{i}, Y_{i}+Y_{-i}\right)\right] \cdot Y_{i}+\beta \cdot\left|x_{i}-x_{i}^{0}\right| \cdot Y_{i}
$$

The social planner must determine the location of the pumping wells ${ }^{10}$ and the water discharges such as the welfare is maximized and the extraction constraints are satisfied. Thus, maximizing the social welfare results in the following program $\mathcal{P}$ :

$$
\begin{aligned}
& \max _{\left\{x_{i}, Y_{i}\right\}_{i=1, \ldots, I}} \sum_{i=1}^{I} V_{i}\left(Y_{i}\right)-T C_{i}\left(Y_{i}, Y_{-i}, x_{i}\right) \\
& \mathrm{s} / \mathrm{t} \quad \bar{Y}\left(x_{i}\right)-\sum_{i=1}^{I} Y_{i} \geq 0 \quad i=1, \ldots, I \\
& x_{i} \geq 0 \quad i=1, \ldots, I \\
& X^{0}-x_{i} \geq 0 \quad i=1, \ldots, I \\
& Y_{i} \geq 0 \quad i=1, \ldots, I
\end{aligned}
$$

As we shall see in the next sections, the objective function of the program $\mathcal{P}$ is not differentiable which makes direct use of first-order condition problematic. In order to gain some intuition on specific difficulties to overcome, the model is first solved in a single city case.

\section{Optimal aquifer use by a single city}

\subsection{Water supply costs}

We assume now that the coastal aquifer is exploited by a single city located at distance $x^{0}$ to the coast. The highest feasible pumping rate from $x^{0}$, by definition $\bar{Y}\left(x^{0}\right)$, is more simply denoted by $Y^{0}$. The population size of this city is $n$. Let us first characterize the optimal location of the well conditionally to the volume of water pumped. Two cases are possible. First, for $Y \leq Y^{0}$ the resource is available at

\footnotetext{
${ }^{10}$ We implicitly assume that each city can be water supplied from only one pumping point. This would be the optimum in case of very high fixed costs associated to the construction of pumping wells.
} 
$x^{0}$. The less costly way to obtain $Y$ is to pump at $x^{0}$ : the city does not bear any surface transportation cost and the pumping cost is minimized because it increases with the distance to the coast. ${ }^{11}$ Second, for $Y>Y^{0}$ water is available upstream at $\bar{x}(Y)>x^{0}$. Since transportation and pumping costs increase with the distance to the coast, the less costly way to obtain $Y$ is to locate pumping at $\bar{x}(Y)$. In that case, according to equation (6), the water table elevation is $\underline{h}$. Thus, the total cost, $T C(Y)$, is:

$$
T C= \begin{cases}\alpha \cdot\left[g\left(x^{0}\right)-h\left(x^{0}, Y\right)\right] \cdot Y & \text { if } Y \leq Y^{0} \\ \alpha \cdot[g(\bar{x}(Y))-\underline{h}] \cdot Y+\beta \cdot\left[\bar{x}(Y)-x^{0}\right] \cdot Y & \text { if } Y^{0}<Y .\end{cases}
$$

The total cost function is continuous everywhere but non differentiable at $Y^{0}$. The main reason is the following. For $Y \leq Y^{0}$, the pumping well is located at $x^{0}$ and conveyance costs are null. For $Y>Y^{0}$, the pumping well has to be located at $\bar{x}(Y)>x^{0}$. The city must pay now a strictly positive conveyance cost. Let's us assume that the city is pumping at $x^{0}$ at a rate $Y^{0}$ corresponding to the maximal feasible rate at this location. A marginal increase of the pumping rate will require to move landward marginally the well location. The whole resource will have now to be conveyed from the pumping well to the city. It follows that, due to surface transportation, the marginal cost jumps upward at $Y^{0}$. The associated discontinuity of the marginal cost is equal to $\beta \cdot Y^{0} \cdot \bar{x}^{\prime}\left(Y^{0}\right)$. As a consequence, the higher is $Y^{0}$ (i.e. $x^{0}$ is far away from the coast) and/or the unit conveyance cost $\beta$, the bigger is the marginal cost discontinuity. One important consequence of the cost non differentiability is that the optimal pumping cannot be derived directly from the first order conditions. Let $M C(Y)$ denotes the marginal supply cost:

$$
M C= \begin{cases}\alpha\left[g\left(x^{0}\right)-h\left(x^{0}, Y\right)\right]-\alpha \frac{\partial h}{\partial Y}\left(x^{0}, Y\right) Y & \text { if } Y \leq Y^{0} \\ \alpha[g(\bar{x}(Y))-\underline{h}]+\alpha \bar{x}^{\prime}(Y) g^{\prime}(\bar{x}(Y)) Y+\beta\left(\bar{x}(Y)-x^{0}\right)+\beta Y \bar{x}^{\prime}(Y) & \text { if } \quad Y^{0}<Y .\end{cases}
$$

For $Y \leq Y^{0}$, the marginal cost of water supply corresponds to the sole marginal cost of pumping. As the water table elevation decreases with pumping, the marginal cost increases on this interval. For

\footnotetext{
${ }^{11}$ In some cases the city may find more profitable to locate the pumping well downstream where the water elevation cost is lower. We assume that the unit transportation cost, $\beta$, is high enough to prevent such a situation to occur. Typically, the condition insuring that no city will pump water downstream writes $\beta>\alpha \frac{d}{d x}[g(x)-h(x, Y)]$.
} 
$Y>Y^{0}$, the marginal cost of water supply is the sum of the marginal pumping cost and the marginal transportation cost. Since the rate of pumping is in that case the maximal feasible rate, the water table is at its minimum $\underline{h}$, see equation (6). The pumping cost increase is only due to the increase of the ground elevation, $g^{\prime}(x)>0$. Moreover, water must be transported from the location of the pumping point to the city location. The two last terms of the second equation (13) correspond to the effect of an increase of water withdrawal on the surface transportation cost. We can finally explicitly characterize the marginal cost discontinuity at $Y^{0}$ :

$$
\lim _{Y \rightarrow Y^{0+}} M C(Y)-\lim _{Y \rightarrow Y^{0-}} M C(Y)=\beta Y^{0} \bar{x}^{\prime}\left(Y^{0}\right)+\alpha Y^{0}\left[\bar{x}^{\prime}\left(Y^{0}\right) g^{\prime}\left(x^{0}\right)+\frac{\partial h}{\partial Y}\left(x^{0}, Y\right)\right]
$$

The first term of the discontinuity is due to the surface transportation of water. The second term corresponds to the fact that for $Y \leq Y^{0}$, the pumping is located in $x^{0}$. The pumping cost increase is only due to a fall of the water table. For $Y>Y^{0}$ an increase of water withdrawals also results in moving landward the pumping location. As ground elevation increases with the distance to the coast, it follows that the depth at which freshwater can be found increases. This results in an increase of the pumping cost. Notice finally that when $Y>Y^{0}$, the marginal cost is an increasing and convex function of extracted water.

\subsection{Optimal withdrawals}

The aggregate marginal utility function, $V^{\prime}($.$) , decreases with Y$. Moreover, this function is increasing and convex with the population size, $n$. Hence, three cases must be distinguished as illustrated in Figure 2.

[Figure 2, here]

Small population case. First, if the population size is small enough, intersection between the marginal utility and the marginal social water supply cost occurs for $Y$ smaller than $Y^{0}$. This is 
the case corresponding to curve (1) on Figure 2, the intersecting point being $Y^{(1)}$. Pumping will be located at $x^{0}$ and because the maximal available flow at this point is greater than $Y^{(1)}$, the resource is abundant. Optimal discharge is characterized by $U^{\prime}(Y / n)=\alpha \cdot\left[g\left(x^{0}\right)-h\left(x^{0}, Y\right)\right]-\alpha \cdot \frac{\partial h}{\partial Y}\left(x^{0}, Y\right) \cdot Y$. The optimum can simply be decentralized to a private or public firm by, first pricing water to users at its marginal cost, second obliging the firm to satisfy the whole demand at this price. Notice that the delegated firm realizes strictly positive profits because of increasing marginal costs. These profits may be extracted by imposing the firm to pay a fixed concession fee. This "small population case" holds if the population size is smaller than $n^{(1)}=Y^{0} / U^{\prime-1}\left(M C\left(Y^{0-}\right)\right)$.

Intermediate population case. In case of an intermediate population size, the marginal utility (curve (2) on Figure 2) does not cross the marginal water supply cost. Total pumping is restricted to be $Y^{0}$. Water is scarce and a scarcity rent $\lambda$,

$$
\lambda=U^{\prime}\left(Y^{0} / n\right)-\alpha \cdot\left[g\left(x^{0}\right)-\underline{h}\right]-\alpha \cdot \frac{\partial h}{\partial Y}\left(x^{0}, Y^{0}\right) \cdot Y^{0},
$$

must be imputed to the resource. It is possible to decentralize the optimum to a private or public firm by imposing on the delegated firm a unit tax corresponding to the scarcity rent. The marginal price of water will be equal to the marginal cost evaluated at $y=Y^{0} / n$ plus the unit royalty equal to the scarcity rent. The frontier of the "intermediate population case" in the population space is such as the population size is greater than $n^{(1)}$ and smaller than $n^{(2)}$ where $n^{(2)}=Y^{0} / U^{\prime-1}\left(\alpha \cdot\left[g\left(x^{0}\right)-\underline{h}\right]+\alpha\right.$. $\left.\bar{x}^{\prime}\left(Y^{0}\right) \cdot g^{\prime}\left(x^{0}\right) \cdot Y^{0}+\beta \cdot Y^{0} \cdot \bar{x}^{\prime}\left(Y^{0}\right)\right)$.

Large population case. Finally, in case of a high population size (i.e. greater than $n^{(2)}$ ), the social marginal utility crosses the marginal water supply cost at $Y^{(3)}$ with $Y^{(3)}>Y^{0}$. This is the case illustrated by curve (3) on Figure 2. Pumping is located upward $x^{0}, x>x^{0}$. The water service may be optimally delegated to a private firm pricing water at its marginal cost and satisfying at this price the whole demand. Therefore, the price faced by a representative user is: $U^{\prime}\left(Y^{(3)} / n\right)$. Because of increasing marginal costs, the firm will realize a strictly positive profit. This profit may be extracted 
by the social planner through a lump-sum fee.

\section{Optimal aquifer use by two cities}

The two cities case will permit to appreciate how marginal cost discontinuities may combine and put in light the nature of externalities created by one city on the other one. As a convention, city 1 is called downstream whereas upstream denotes city 2.

\subsection{Social costs}

Let $Y_{1}^{0}$ and $Y_{2}^{0}$ respectively denote the maximum pumping rate from $x_{1}^{0}$ and $x_{2}^{0}$ without pumping elsewhere: $Y_{1}^{0}=\bar{Y}\left(x_{1}^{0}\right)$ and $Y_{2}^{0}=\bar{Y}\left(x_{2}^{0}\right)$. For any pair $\left(Y_{1}, Y_{2}\right)$, the security constraints require pumpings to occur at a distance from the coast at least equal to $\bar{x}(Y), Y=Y_{1}+Y_{2}$. For $Y \leq Y_{1}^{0}$ then $\bar{x}(Y)$ is downstream the location of city 2 . The cost minimization results in pumping to be respectively located at $x_{1}^{0}$ and $x_{2}^{0}$. For $Y \in\left(Y_{1}^{0}, Y_{2}^{0}\right]$ then $\bar{x}(Y)$ is upstream $x_{1}^{0}$ and downstream $x_{2}^{0}$. Transportation and pumping cost minimization requires the pumping well of the downstream city to be located at $\bar{x}(Y)$ whereas the upstream city keeps on pumping at $x_{2}^{0}$. Finally, for $Y>Y_{2}^{0}$ costs minimization requires that both cities pump at some point $\bar{x}(Y)$ located upstream the upstream city. Thus, the social total water supply cost function, $T C^{s}\left(Y_{1}, Y_{2}\right)$, is:

$$
T C^{s}= \begin{cases}\sum_{i=1,2} \alpha\left[g\left(x_{i}^{0}\right)-h\left(x_{i}^{0}, Y\right)\right] Y_{i} & \text { if } Y \leq Y_{1}^{0} \\ \alpha[g(\bar{x}(Y))-\underline{h}] Y_{1}+\alpha\left[g\left(x_{2}^{0}\right)-h\left(x_{2}^{0}, Y\right)\right] Y_{2}+\beta\left[\bar{x}(Y)-x_{1}^{0}\right] Y_{1} & \text { if } Y_{1}^{0}<Y \leq Y_{2}^{0} \\ \sum_{i=1,2} \alpha[g(\bar{x}(Y))-\underline{h}] Y_{i}+\beta\left[\bar{x}(Y)-x_{i}^{0}\right] Y_{i} & \text { if } Y_{2}^{0}<Y .\end{cases}
$$

From these equations, it can be seen that two types of externalities must be taken into account in order to determine the optimal allocation of water. First, an increase of the pumping rate of any city will result in a decrease of the water table. This induces an increase of pumping costs. This type of reciprocal pumping cost externality has been studied by many authors. See for example Swallow (2000) 
for a recent work integrating variable costs. Second, pumpings create another type of cost externality. When one city increases its pumping rate, the last feasible pumping point may move landward. This results in an increase of the surface transportation cost. It follows that pumpings may create both a pumping cost externality and a transportation cost externality. Notice that for $Y_{1}^{0}<Y \leq Y_{2}^{0}$, the transportation cost externality in only created by the upstream city on the downstream one whereas for $Y_{2}^{0}<Y$ this externality is reciprocal. As in the one city case, it can easily be shown that the total cost function is continuous, increasing and convex. However, the social marginal water supply cost functions, $M C_{1}^{s}=\partial T C^{s} / \partial Y_{1}$ for the downstream city and $M C_{2}^{s}=\partial T C^{s} / \partial Y_{2}$ for the upstream city, are discontinuous at $\left(Y_{1}, Y_{2}\right)$ such as either $Y_{1}+Y_{2}=Y_{1}^{0}$, or $Y_{1}+Y_{2}=Y_{2}^{0}$. These functions are:

$$
\begin{gathered}
M C_{1}^{s}= \begin{cases}\alpha\left[g\left(x_{1}^{0}\right)-h\left(x_{1}^{0}, Y\right)\right]-\alpha \sum_{i=1,2} \frac{\partial h}{\partial Y}\left(x_{i}^{0}, Y\right) Y_{i} & \text { if } Y \leq Y_{1}^{0} \\
\left.\alpha[g(\bar{x}(Y))-\underline{h}]+\bar{x}^{\prime}(Y) g^{\prime}(\bar{x}(Y)) Y_{1}\right]+\beta\left[\left(\bar{x}(Y)-x_{1}^{0}\right)+Y_{1} \bar{x}^{\prime}(Y)\right] & \\
-\alpha \frac{\partial h}{\partial Y}\left(x_{2}^{0}, Y\right) Y_{2} & \text { if } Y_{1}^{0}<Y \leq Y_{2}^{0} \\
\alpha[g(\bar{x}(Y))-\underline{h}]+\beta\left[\bar{x}(Y)-x_{1}^{0}\right]+\left(Y_{1}+Y_{2}\right) \bar{x}^{\prime}(Y)\left[\alpha g^{\prime}(\bar{x}(Y))+\beta\right] & \text { if } Y_{2}^{0}<Y\end{cases} \\
M C_{2}^{s}= \begin{cases}\alpha\left[g\left(x_{2}^{0}\right)-h\left(x_{2}^{0}, Y\right)\right]-\alpha \sum_{i=1,2} \frac{\partial h}{\partial Y}\left(x_{i}^{0}, Y\right) Y_{i} & \text { if } Y \leq Y_{1}^{0} \\
\left.\alpha\left[g\left(x_{2}^{0}\right)-h\left(x_{2}^{0}, Y\right)\right]-\frac{\partial h}{\partial Y}\left(x_{2}^{0}, Y\right) Y_{2}\right]+Y_{1} \bar{x}^{\prime}(Y)\left[\beta+\alpha g^{\prime}(\bar{x}(Y))\right] & \text { if } Y_{1}^{0}<Y \leq Y_{2}^{0} \\
\alpha[g(\bar{x}(Y))-\underline{h}]+\beta\left[\bar{x}(Y)-x_{2}^{0}\right]+\left(Y_{1}+Y_{2}\right) \bar{x}^{\prime}(Y)\left[\alpha g^{\prime}(\bar{x}(Y))+\beta\right] & \text { if } Y_{2}^{0}<Y .\end{cases}
\end{gathered}
$$

Marginal costs are piecewise increasing and convex. They present a double discontinuity. First at $Y_{1}+Y_{2}=Y_{1}^{0}, M C_{i}^{s}, i=1,2$ as a function of $Y_{i}$ jumps upward:

$$
\lim _{Y \rightarrow Y_{1}^{0+}} M C_{i}^{s}-\lim _{Y \rightarrow Y_{1}^{0-}} M C_{i}^{s}=\beta Y_{1} \bar{x}^{\prime}\left(Y_{1}^{0}\right)+\alpha Y_{1}\left[g^{\prime}\left(x_{1}^{0}\right) \bar{x}^{\prime}\left(Y_{1}^{0}\right)+\frac{\partial h}{\partial Y}\left(x_{1}^{0}, Y_{1}^{0}\right)\right]
$$

The interpretation of this discontinuity is similar to the discussion following equation (14). Let us start from an initial situation where total discharge is $Y_{1}^{0}$ which implies that pumping occurs at $x_{1}^{0}$ for city 1 and at $x_{2}^{0}$ for city 2 . If global pumping increases marginally, pumping location of the downstream city has to move marginally landward whereas the upstream city keeps on pumping at $x_{2}^{0}$. This has two 
cost effects. First there is a transportation cost effect: all the resource extracted for the downstream city has to be transported from the pumping point to the city. The associated cost discontinuity is $\beta Y_{1} \bar{x}^{\prime}\left(Y_{1}^{0}\right)$. Second, there is a pumping cost effect: since the pumping location is upstream $x_{1}^{0}$ then the ground level has now an effect on costs $\alpha Y_{1}\left(g^{\prime}\left(x_{1}^{0}\right) \bar{x}^{\prime}\left(Y_{1}^{0}\right)\right)$. Moreover, since the pumping rate is the maximum feasible rate, the water table elevation is $\underline{h}$ whereas it used to decrease with $Y$ for $Y<Y_{1}^{0}$. The marginal cost discontinuity gap is $\alpha Y_{1} \frac{\partial h}{\partial Y}\left(x_{1}^{0}, Y_{1}^{0}\right)$.

Let us now consider the case where $Y_{1}+Y_{2}=Y_{2}^{0}$. Now, $M C_{i}$ as a function of $Y_{i}$ also presents a discontinuity:

$$
\lim _{Y \rightarrow Y_{2}^{0+}} M C_{i}^{s}-\lim _{Y \rightarrow Y_{2}^{0-}} M C_{i}^{s}=\beta Y_{2} \bar{x}^{\prime}\left(Y_{2}^{0}\right)+\alpha Y_{2}\left[g^{\prime}\left(x_{2}^{0}\right) \bar{x}^{\prime}\left(Y_{2}^{0}\right)+\frac{\partial h}{\partial Y}\left(x_{2}^{0}, Y_{2}^{0}\right)\right]
$$

The interpretation of this social marginal cost discontinuity is similar to equation (19) replacing city 1 by city 2 .

\subsection{Optimal withdrawals}

Each city is defined by its population size $n_{i}$ and its distance to the coast $x_{i}^{0}$. The following analysis characterizes the optimal aquifer use as a function of $\left(n_{1}, n_{2}\right)$ for given locations $\left(x_{1}^{0}, x_{2}^{0}\right)$.

\subsubsection{Very small population sizes case}

Let $y_{i}^{(1)}$, with $i=1,2$, denotes the optimal consumption level per capita solution to:

$$
U^{\prime}\left(y_{i}\right)=\alpha\left[g\left(x_{i}^{0}\right)-h\left(x_{i}^{0}, Y\right)\right]-\alpha \sum_{i=1,2} \frac{\partial h}{\partial Y}\left(x_{i}^{0}, Y\right) Y_{i}
$$

Let $Y_{i}^{(1)}=n_{i} y_{i}^{(1)}$ denotes the aggregate water consumption of cities $i$ and $Y^{(1)}$ the associated total pumping, $Y^{(1)}=Y_{1}^{(1)}+Y_{2}^{(1)}$. For sufficiently small population sizes, a quantity $y_{i}^{(1)}$ can be allocated to each consumer of city $i$. Water pumpings occur at $x_{1}^{0}$ and $x_{2}^{0}$ and there are no transportation costs. Population sizes belong to this case while $n_{1} y_{1}^{(1)}+n_{2} y_{2}^{(1)} \leq Y_{1}^{0}$. This defines zone 1 in the $\left(n_{1}, n_{2}\right)$ space, see Figure 3. This frontier is studied in details in Appendix A. 
[Figure 3, here]

As the marginal social cost differs for the two cities due to different pumping costs, the water price faced by the consumers is different. In fact, because of higher pumping costs, $g\left(x_{2}^{0}\right)-h\left(x_{2}^{0}, Y^{(1)}\right)>$ $g\left(x_{1}^{0}\right)-h\left(x_{1}^{0}, Y^{(1)}\right)$, we have $y_{2}^{(1)}<y_{1}^{(1)}$.

It is finally interesting to notice that even in that very small population sizes case, water pumpings of cities create some externalities. Let $M C_{i}^{p}$ denotes the private marginal cost of city $i$. We have:

$$
M C_{i}^{s}-M C_{i}^{p}=-\alpha \frac{\partial h}{\partial Y}\left(x_{j}^{0}, Y^{(1)}\right) Y_{j}^{(1)}>0 \quad i, j=1,2 \quad i \neq j
$$

A private management of each city is not optimal because it does not take into account the fact that withdrawal group decrease the water table and so increase pumping cost of the other city. It follows that the delegation of the service to a private firm will require a system of differentiated unit taxes ${ }^{12}$, $\mu_{i}^{(1)}=-\alpha \frac{\partial h}{\partial Y}\left(x_{j}^{0}, Y^{(1)}\right) Y_{j}^{(1)} \quad i, j=1,2 \quad i \neq j$. Notice that the unit tax of a city increases with the population size of the city, the cost externality being higher in that case.

\subsubsection{Small population sizes case}

Let us now consider population sizes outside zone 1. The first problem is to determine if it is efficient to increase global pumping. A discharge rate increase will move the downstream city pumping point landwards. Hence the downstream city will have to bear conveyance costs. Intuition suggests that it is not optimal to increase total withdrawals while $\left(n_{1}, n_{2}\right)$ remains near the locus of the zone 1 frontier. The optimal solution consists, in this case, in restricting total pumping to be $Y_{1}^{0}$ and in equalizing the marginal net utilities between consumers. Let $y_{i}^{(2)}, i=1,2$ denotes the optimal consumption level

\footnotetext{
${ }^{12}$ We consider here the decentralization of water services to private or public firms via a system of unit fees because it corresponds to the current French water sector regulation framework situation. In France, administration is centred in six river basin committees and six river basin financial agencies (AFBs). The AFBs which award grants and loans, develop long-term plans, collect and analyze water data, conduct studies and finance research, also set two fees to be paid by water users: one for water withdrawals and the other for pollution. The fees aim at providing incentives for users and also form a fund to encourage better water use through grants or soft loans. The ultimate objective of this system of taxes is to provide feasible and and effective solutions to the major concerns about public water management: water scarcity, pollution and conjunctive use of ground and surface water. Thus, the system of spatially differentiated taxes depicted in this paper may fit the French water regulation framework.
} 
per capita in this population size zone. Then the optimal consumptions $y_{1}^{(2)}$ and $y_{2}^{(2)}$ are such that $Y_{1}^{0}=n_{1} y_{1}^{(2)}+n_{2} y_{2}^{(2)}$ and:

$$
U^{\prime}\left(y_{2}^{(2)}\right)-U^{\prime}\left(y_{1}^{(2)}\right)=\alpha\left[g\left(x_{2}^{0}\right)-h\left(x_{2}^{0}, Y_{1}^{0}\right)\right]-\alpha\left[g\left(x_{1}^{0}\right)-h\left(x_{1}^{0}, Y_{1}^{0}\right)\right]
$$

Since the marginal social cost is higher in the upstream city because of a higher pumping cost, we have $y_{1}^{(2)}>y_{2}^{(2)}$. A scarcity rent $\lambda^{(2)}$, equal to $U^{\prime}\left(y_{i}^{(2)}\right)-M C_{i}^{s}\left(n_{1} y_{1}^{(2)}, n_{2} y_{2}^{(2)}\right)>0$, is now associated to the resource. This scarcity rent is directly related to the social marginal cost discontinuity when total pumping is $Y_{1}^{0}$. This solution prevails while the scarcity rent is smaller than the marginal social cost discontinuity gap, i.e. while:

$$
\lambda^{(2)} \leq Y_{1}^{(2)} \bar{x}^{\prime}\left(Y_{1}^{0}\right)\left[\beta+\alpha g^{\prime}\left(x_{1}^{0}\right)\right]+\alpha \frac{\partial h}{\partial Y}\left(x_{1}^{0}, Y_{1}^{0}\right) Y_{1}^{(2)},
$$

where $Y_{i}^{(2)}$ is the optimal consumption of city $i$. This inequality defines zone 2 in the the $\left(n_{1}, n_{2}\right)$ space, see Figure 3. As an equality, inequality (24) defines the North-East frontier of zone 2 (see Figure 3 and Appendix A for more details on the shape of this frontier).

Let us finally investigate the delegation problem of the water utilities. In this population size space, we still have:

$$
M C_{i}^{s}-M C_{i}^{p}=-\alpha \frac{\partial h}{\partial Y}\left(x_{j}^{0}, Y_{1}^{0}\right) Y_{j}^{(2)}>0 \quad i, j=1,2 \quad i \neq j
$$

so the unit tax correcting the pumping cost externalities, $\mu_{i}^{(2)}$, is still equal to $-\alpha \frac{\partial h}{\partial Y}\left(x_{j}^{0}, Y_{1}^{0}\right) Y_{j}^{(2)} i, j=$ $1,2 i \neq j$. Delegated firm $i$ must be charged a unit tax equal to $\lambda^{(2)}+\mu_{i}^{(2)}$. This tax takes into account the scarcity of the resource and makes the firm internalize the cost externalities created by withdrawals on the other city consumers. If firms are asked, first to price water at their marginal cost including the unit taxes and, second to satisfy the whole demand at this price, then water discharges and pumping locations will be optimal. 


\subsubsection{Intermediate population sizes case}

Next, suppose that $\left(n_{1}, n_{2}\right)$ is outside zones 1 and 2 but is not far from the North-East frontier of zone

2. In such a case, the downstream city exploits the coastal aquifer from a point located upstream $x_{1}^{0}$ but downstream $x_{2}^{0}$. The upstream city keeps on exploiting the aquifer from $x_{2}^{0}$. Let us note $y_{1}^{(3)}$ and $y_{2}^{(3)}$ the optimal consumption per capita for city 1 and 2 in this case. These consumptions equalize the marginal utility and the marginal social cost:

$$
U^{\prime}\left(y_{1}\right)=M C_{1}^{s}\left(n_{1} y_{1}, n_{2} y_{2}\right) \text { and } U^{\prime}\left(y_{2}\right)=M C_{2}^{s}\left(n_{1} y_{1}, n_{2} y_{2}\right)
$$

with $\left.\left.n_{1} y_{1}+n_{2} y_{2} \in\right] Y_{1}^{0}, Y_{2}^{0}\right]$. The North-East frontier of this area is defined by:

$$
\bar{x}\left(n_{1} y_{1}^{(3)}+n_{2} y_{2}^{(3)}\right) \leq x_{2}^{0}
$$

where $y_{1}^{(3)}$ and $y_{2}^{(3)}$ solutions of (26) depend upon $n_{1}$ and $n_{2}$. We show in Appendix A that the shape of the frontier is the one described on Figure 3.

Concerning the delegation of the water service in this population size case, we have:

$$
\begin{aligned}
M C_{1}^{s}-M C_{1}^{p} & =-\alpha \frac{\partial h}{\partial Y}\left(x_{2}^{0}, Y^{(3)}\right) Y_{2}^{(3)} \\
M C_{2}^{s}-M C_{2}^{p} & =\beta Y_{1}^{(3)} \bar{x}^{\prime}\left(Y^{(3)}\right)+\alpha Y_{1}^{(3)} \bar{x}^{\prime}\left(Y^{(3)}\right) g^{\prime}\left(\bar{x}\left(Y^{(3)}\right)\right)
\end{aligned}
$$

For the downstream city, the marginal social cost is higher than the marginal private cost because the water pumping reduces the water table in $x_{2}^{0}$ and so, increases the pumping costs of the upstream city. When pumping of the upstream city increases, the cost of the downstream city increases because of two effects: the pumping location moves landwards so both the transportation and the pumping cost increase. How possible is it to decentralize the aquifer management in zone 3 ? It is possible to delegate water services to a private or public firms by first, pricing water at its marginal social cost (private cost plus a unit tax $\left.\mu_{i}^{(3)}=M C_{i}^{s}-M C_{i}^{p}\right)$ and second, obliging firms to satisfy the whole demand. Because of increasing marginal costs, firms will realize positive profits that may be extracted by a lump-sum fee. 


\subsubsection{Large population sizes case}

Let us now consider population sizes $\left(n_{1}, n_{2}\right)$ outside zones 1 to 3 but not too far from the zone 3 frontier. The problem is now to determine whether it is more efficient to maintain total water discharge at a level $Y_{2}^{0}$ or to increase pumping. Notice that this discussion is similar to the small population sizes case, replacing city 1 by city 2 . When total withdrawals are $Y_{2}^{0}$ pumpings occur at $x_{2}^{0}$ and the water table is at this point $\underline{h}$. So the pumping cost is the same for both cities and the marginal cost only differs because of transportation. The optimal allocation of water consists, in this case, in restricting pumping at $Y_{2}^{0}$ and in equalizing the marginal net utilities between consumers. Let $y_{i}^{(4)}$, $i=1,2$ denotes the optimal consumption level per capita in this population size zone. The optimal consumptions $y_{1}^{(4)}$ and $y_{2}^{(4)}$ are such that $n_{1} y_{1}^{(4)}+n_{2} y_{2}^{(4)}=Y_{2}^{0}$ and:

$$
U^{\prime}\left(y_{1}^{(4)}\right)-U^{\prime}\left(y_{2}^{(4)}\right)=\beta\left(x_{2}^{0}-x_{1}^{0}\right)
$$

Because $U^{\prime}$ decreases with $y$, the optimal water consumption per capita is smaller in the downstream city than in the upstream city, $y_{1}^{(4)}<y_{2}^{(4)}$. A scarcity rent $\lambda^{(4)}$, equal to $U^{\prime}\left(y_{i}^{(4)}\right)-M C_{i}^{s}\left(n_{1} y_{1}^{(4)}, n_{2} y_{2}^{(4)}\right)>$ 0 , is now associated to the resource. This scarcity rent is directly related to the social marginal cost discontinuity when total pumping is $Y_{2}^{0}$. This solution prevails while the scarcity rent is smaller than the marginal social cost discontinuity gap, i.e. while:

$$
\lambda^{(4)} \leq Y_{2}^{(4)} \bar{x}^{\prime}\left(Y_{2}^{0}\right)\left[\beta+\alpha g^{\prime}\left(x_{2}^{0}\right)\right]+\alpha \frac{\partial h}{\partial Y}\left(x_{2}^{0}, Y_{2}^{0}\right) Y_{2}^{(4)}
$$

As an equality, this condition defines the North-East frontier of zone 4 which is the part of population sizes space $\left(n_{1}, n_{2}\right)$ such that the optimal consumptions are the one depicted above (see Figure 3 and Appendix A for more details on the shape of this frontier).

Last let us remark that for population sizes in this zone, we have:

$$
\begin{aligned}
M C_{1}^{s}-M C_{1}^{p} & =-\alpha \frac{\partial h}{\partial Y}\left(x_{2}^{0}, Y_{2}^{0}\right) Y_{2}^{(4)} \\
M C_{2}^{s}-M C_{2}^{p} & =\beta Y_{1}^{(4)} \bar{x}^{\prime}\left(Y_{2}^{0}\right)+\alpha Y_{1}^{(4)} \bar{x}^{\prime}\left(Y_{2}^{0}\right) g^{\prime}\left(x_{2}^{0}\right),
\end{aligned}
$$


these differences being respectively denoted by $\mu_{1}^{(4)}$ and $\mu_{2}^{(4)}$. In order to make the consumers of a city internalize the cost externalities created by their withdrawals on the other consumers, the delegated firm $i$ must be charged a the unit tax equal to $\lambda^{(4)}+\mu_{i}^{(4)}$.

\subsubsection{Very large population sizes case}

Finally we examine the case of very important population sizes that is populations that do not belong to zones 1 to 4 . In that case, pumping of both cities is located at $\bar{x}\left(Y_{1}+Y_{2}\right)>x_{2}^{0}$. Let us note $y_{1}^{(5)}$ and $y_{2}^{(5)}$ the optimal consumption per capita in city 1 and 2 . These consumptions equalize the marginal utility and the marginal social cost, that is:

$$
U^{\prime}\left(y_{1}\right)=M C_{1}^{s}\left(n_{1} y_{1}, n_{2} y_{2}\right) \text { and } U^{\prime}\left(y_{2}\right)=M C_{2}^{s}\left(n_{1} y_{1}, n_{2} y_{2}\right)
$$

with $\left.\left.n_{1} y_{1}+n_{2} y_{2} \in\right] Y_{2}^{0}, \bar{Y}^{0}\right]$. Notice that the consumption per capita in the downstream city, $y_{1}^{(5)}$, is still smaller than consumption in the upstream city $y_{2}^{(5)}$ because of higher transportation costs. Water must be sold at price $U^{\prime}\left(y_{1}^{(5)}\right)$ in the downstream city and at price $U^{\prime}\left(y_{2}^{(5)}\right)$ in the upstream one. Hence, the price in the downstream city is higher than the price in the upward city.

In this population size zone, we have:

$$
\begin{aligned}
M C_{1}^{s}-M C_{1}^{p} & =\beta Y_{2}^{(5)} \bar{x}^{\prime}\left(Y^{(5)}\right)+\alpha Y_{2}^{(5)} \bar{x}^{\prime}\left(Y^{(5)}\right) g^{\prime}\left(\bar{x}\left(Y^{(5)}\right)\right) \\
M C_{2}^{s}-M C_{2}^{p} & =\beta Y_{1}^{(5)} \bar{x}^{\prime}\left(Y^{(5)}\right)+\alpha Y_{1}^{(5)} \bar{x}^{\prime}\left(Y^{(5)}\right) g^{\prime}\left(\bar{x}\left(Y^{(5)}\right)\right)
\end{aligned}
$$

When pumping of one city increases, the cost of the other city increases because of two effects: the pumping location moves landwards so both the transportation and the pumping cost increase. It is possible to delegate water services to private or public firms by first, pricing water at its marginal social cost (private cost plus a unit tax $\mu_{i}^{(5)}=M C_{i}^{s}-M C_{i}^{p}$ ) and second, obliging the firms to satisfy the whole demand. Because of increasing marginal costs, firms will realize positive profits that may be extracted by a lump-sum fee. It is interesting to notice that the unit fee to be asked to city $i$ increases 
with the population size of city $j, i, j=1,2$ and $i \neq j$.

\subsubsection{Summary and discussion}

Let us finally briefly summarize in this paragraph the characteristics of the optimum in the five population size cases and the characteristics of the unit fees to be asked to delegated firms.

[Table 1, here]

Five population zones have been characterized. For population sizes belonging to zones 1 and 2, there are no transportation costs. The consumption per capita is higher for city 1 consumers than for city 2 consumers because of lower pumping costs. In zone 4 and 5, as the location of pumping is the same for both cities, the cost of pumping is identical. The consumption per capita is in that case lower for city 1 consumers because the cost of water surface transportation is higher. In the case of intermediate population sizes, the cost of pumping is lower for city 1 . However, those users must bear a transportation cost whereas pumping of city 2 is located at $x_{2}^{0}$. It follows that $y_{1}$ may be either greater or smaller than $y_{2}$ in that case. A scarcity rent must be imputed to the aquifer for populations belonging to zone 2 and 4 . This rent is directly related to the marginal social cost discontinuities. Finally, in the five population sizes zone, the royalties that must be charged to delegated firms are different from one city to another. Generally, there is no simple relation between the tax rates charged to cities and the generic parameters of the model. Yet, the tax system offers a particular characteristic that may create difficulties under some circumstances. Taxes aim at correcting differences between social and private marginal costs. So, the more the population size of a city is small with respect to the total population, the more this difference is important. It follows that smaller cities will be charged higher taxes. It is not sure that such a type of conclusion will be admitted without difficulties by users. Experience shows that margin analysis are in general not understood and that their consequences are accepted only with difficulty. 
Notice that the system of taxes to be implemented for restoring optimality aims at correcting differences between social and private marginal costs. So, the important factor driving this tax system is the repartition of populations over the aquifer. This result should be compared to the characteristics of the tax schedule obtained by Cummings (1971) or by Green and Sunding (2000). In these dynamic models, optimal pumping taxes decrease away from the coastline. This result holds because the effect of pumping on seawater intrusion depends on the location of pumping, the idea being that, on the shortrun, pumping groundwater closer to the coast causes more intrusion that pumping further inland. It immediatly follows that Pigouvian taxes are higher for users located near the coast where the marginal damage created by pumping is higher. Here, as we consider the long-run static equilibrium, the damage created by pumping one more unit of water is the same whatever is the location of the pumping. This is the result of the perfect hydraulic conductivity assumption of the hydrological model: any action that affects a part of aquifer has the same impact on the whole aquifer. Notice, that this assumption is required for deriving an analytical solution for the interface position. It follows that the characteristics of the tax schedule to be implemented in our model and depicted in Table 1, differ crucially from those of the previous works.

\section{Conclusion}

We have presented in this paper a spatial model for managing a coastal aquifer under sea water intrusion conditions. Our analyze is directly set on a standard hydrological model of sea water intrusion in a coastal aquifer. We have incorporated some relevant physical parameters in order to describe such a water resource and we have considered explicitly two types of cost: a pumping cost depending on water elevation and a surface transportation cost. We have characterized the optimal use of this groundwater resource. In particular, we have determined the optimal location of pumping points and the efficient withdrawal rates. Finally, we have characterized the system of taxes that must be asked to delegated 
private or public water utilities in order to decentralize the optimum. We have limit our analysis to the implementation of the optimum through a system of unit taxes as it corresponds to the current regulatory framework of the French Water Agencies. Of course some other economical tools, such as water markets, could also be considered. It would require to clearly specify the property rights of upstream and downstrem users.

The preceding analysis has shown that the optimal management of a coastal aquifer under saline intrusion conditions in a decentralized economy is possible using a tax system. Although city exploit the same aquifer, a spatially differentiated tax schedule in generally required. For a sake of simplicity, we have assumed that resource value is the same for all consumers. It follows that optimal consumption per capita for a given cost is the same. In a more realistic model taking into account heterogeneity of consumers, this result may no more hold because city with high access costs may have high valuation for water. Nevertheless, the result of spatially differentiated taxes still remains: they result from externalities created by cities the ones on the others. 


\section{A Zoning of populations in the two cities case}

\section{A.1 Zone 1}

The North-East frontier of zone 1 , in the $\left(n_{1}, n_{2}\right)$ space, is defined by the following system of equations:

$$
\begin{aligned}
U^{\prime}\left(y_{1}\right) & =\alpha\left[g\left(x_{1}^{0}\right)-h\left(x_{1}^{0}, Y_{1}^{0}\right)\right]-\alpha \sum_{i=1,2} \frac{\partial h}{\partial Y}\left(x_{i}^{0}, Y_{1}^{0}\right) Y_{i} \\
U^{\prime}\left(y_{2}\right) & =\alpha\left[g\left(x_{2}^{0}\right)-h\left(x_{2}^{0}, Y_{1}^{0}\right)\right]-\alpha \sum_{i=1,2} \frac{\partial h}{\partial Y}\left(x_{i}^{0}, Y_{1}^{0}\right) Y_{i} \\
Y_{1}^{0} & =n_{1} y_{1}+n_{2} y_{2} .
\end{aligned}
$$

Differentiating totally (A.1)-(A.2) gives:

$$
\frac{\mathrm{d} y_{2}}{\mathrm{~d} n_{1}}=\left[\frac{y_{2} \Delta}{U_{2}^{\prime \prime}\left(y_{2}\right)-n_{2} \Delta}\right] \frac{\mathrm{d} n_{2}}{\mathrm{~d} n_{1}} \text { and } \frac{\mathrm{d} y_{1}}{\mathrm{~d} n_{1}}=\frac{U_{2}^{\prime \prime}\left(y_{2}\right)}{U_{1}^{\prime \prime}\left(y_{1}\right)}\left[\frac{y_{2} \Delta}{U_{2}^{\prime \prime}\left(y_{2}\right)-n_{2} \Delta}\right] \frac{\mathrm{d} n_{2}}{\mathrm{~d} n_{1}}
$$

with $\Delta=\frac{\alpha}{2} \sqrt{\frac{2}{k} \frac{a^{2}}{1+a} \frac{1}{R-Y_{1}^{0}}}\left(\sqrt{x_{2}^{0}}-\sqrt{x_{1}^{0}}\right)>0$. Differentiating totally (A.3) and using (A.4), we get:

$$
\frac{\mathrm{d} n_{2}}{\mathrm{~d} n_{1}}<0 \Leftrightarrow U_{1}^{\prime \prime}\left(y_{1}\right)-n_{1} \Delta<0
$$

which is satisfied. The North-East frontier of zone $1 n_{2}\left(n_{1}\right)$ is a decreasing function. Notice that when $n_{2}=0$, the maximal population size for city 1 (denoted by $n_{1}^{(1)}$ ) is $n^{(1)}$ defined in the one city case with $x^{0}=x_{1}^{0}$. For $n_{1}=0$, the maximal population size for city 2 is denoted by $n_{2}^{(1)}$.

\section{A.2 Zone 2}

The North-East frontier of zone 2 , in the $\left(n_{1}, n_{2}\right)$ space, is defined by the following system of equations:

$$
\begin{aligned}
U^{\prime}\left(y_{1}\right) & =\alpha\left[\left[g\left(x_{1}^{0}\right)-\underline{h}\right]+\bar{x}^{\prime}\left(Y_{1}^{0}\right) g^{\prime}\left(x_{1}^{0}\right) Y_{1}\right]+\beta Y_{1} \bar{x}^{\prime}\left(Y_{1}^{0}\right)-\alpha \frac{\partial h}{\partial Y}\left(x_{2}^{0}, Y_{1}^{0}\right) Y_{2} \\
U^{\prime}\left(y_{2}\right) & =\alpha\left[\left[g\left(x_{2}^{0}\right)-h\left(x_{2}^{0}, Y_{1}^{0}\right)\right]+\bar{x}^{\prime}\left(Y_{1}^{0}\right) g^{\prime}\left(x_{1}^{0}\right) Y_{1}\right]+\beta Y_{1} \bar{x}^{\prime}\left(Y_{1}^{0}\right)-\alpha \frac{\partial h}{\partial Y}\left(x_{2}^{0}, Y_{1}^{0}\right) Y_{2} \\
Y_{1}^{0} & =n_{1} y_{1}+n_{2} y_{2} .
\end{aligned}
$$

By totally differentiating the system (A.6)-(A.8), we get:

$$
\frac{\mathrm{d} n_{2}}{\mathrm{~d} n_{1}}=-\frac{U_{1}^{\prime \prime}\left(y_{1}\right)}{U_{2}^{\prime \prime}\left(y_{2}\right)} \frac{U_{2}^{\prime \prime}\left(y_{2}\right)+n_{2}\left(\alpha \frac{\partial h}{\partial Y}\left(x_{2}^{0}, Y_{1}^{0}\right)+\bar{x}^{\prime}\left(Y_{1}^{0}\right)\left(g^{\prime}\left(x_{1}^{0}\right)+\beta\right)\right)}{U_{1}^{\prime \prime}\left(y_{1}\right)+n_{1}\left(\alpha \frac{\partial h}{\partial Y}\left(x_{2}^{0}, Y_{1}^{0}\right)+\bar{x}^{\prime}\left(Y_{1}^{0}\right)\left(g^{\prime}\left(x_{1}^{0}\right)+\beta\right)\right)}
$$


which can be positive or negative. Typically, the shape of North-East frontier of zone 2 is the one described on Figure 3. Last, for $n_{2}=0$, the maximal population size for city 1 (denoted by $n_{1}^{(2)}$ ) is $n^{(2)}$ defined in the one city case with $x^{0}=x_{1}^{0}$. For $n_{1}=0$, the maximal population size for city 2 (denoted by $\left.n_{2}^{(2)}\right)$ is still $n_{2}^{(1)}$.

\section{A.3 Zone 3}

The North-East frontier of zone 3 , in the $\left(n_{1}, n_{2}\right)$ space, is defined by the following system of equations:

$$
\begin{aligned}
U^{\prime}\left(y_{1}\right) & =\alpha\left[\left[g\left(x_{2}^{0}\right)-\underline{h}\right]+\bar{x}^{\prime}(Y) g^{\prime}\left(x_{2}^{0}\right) Y_{1}\right]+\beta\left[\left(x_{2}^{0}-x_{1}^{0}\right)+Y_{1} \bar{x}^{\prime}\left(Y_{2}^{0}\right)\right]-\alpha \frac{\partial h}{\partial Y}\left(x_{2}^{0}, Y_{2}^{0}\right) Y_{2}( \\
U^{\prime}\left(y_{2}\right) & =\alpha\left[\left[g\left(x_{2}^{0}\right)-\underline{h}\right]-\frac{\partial h}{\partial Y_{2}^{0}}\left(x_{2}^{0}, Y_{2}^{0}\right) Y_{2}\right]+Y_{1} \bar{x}^{\prime}\left(Y_{2}^{0}\right)\left[\beta+\alpha g^{\prime}\left(x_{2}^{0}\right)\right] \\
Y_{2}^{0} & =n_{1} y_{1}+n_{2} y_{2} .
\end{aligned}
$$

By differentiating totally the system (A.10)-(A.12), it is not possible to sign $\frac{\mathrm{d} n_{2}}{\mathrm{~d} n_{1}}$ so we get:

$$
\frac{\mathrm{d} n_{2}}{\mathrm{~d} n_{1}} \leq 0
$$

Typically, the shape of North-East frontier of zone 3 is the one described on Figure 3. Notice that for $n_{1}=0$, the maximal population size for city 2 (denoted by $n_{2}^{(3)}$ ) is $n^{(1)}$ defined in the one city case with $x^{0}=x_{2}^{0}$. For $n_{2}=0$, the maximal population size for city 1 (denoted by $\left.n_{1}^{(3)}\right)$ is:

$$
n_{1}^{(3)}=Y_{2}^{0} / U^{\prime}-1\left[\alpha\left[g\left(x_{2}^{0}\right)-\underline{h}\right]+\alpha \bar{x}^{\prime}\left(Y_{2}^{0}\right) g^{\prime}\left(x_{2}^{0}\right) Y_{2}^{0}+\beta\left(x_{2}^{0}-x_{1}^{0}\right)+\beta Y_{2}^{0} \bar{x}^{\prime}\left(Y_{2}^{0}\right)\right]
$$

\section{A.4 Zone 4}

The North-East frontier of zone 4 , in the $\left(n_{1}, n_{2}\right)$ space, is defined by the following system of equations:

$$
\begin{aligned}
U^{\prime}\left(y_{1}\right) & =\alpha\left[g\left(x_{2}^{0}\right)-\underline{h}\right]+\beta\left[x_{2}^{0}-x_{1}^{0}\right]+Y_{2}^{0} \bar{x}^{\prime}\left(Y_{2}^{0}\right)\left[\alpha g^{\prime}\left(x_{2}^{0}\right)+\beta\right] \\
U^{\prime}\left(y_{2}\right) & =\alpha\left[g\left(x_{2}^{0}\right)-\underline{h}\right]+Y_{2}^{0} \bar{x}^{\prime}\left(Y_{2}^{0}\right)\left[\alpha g^{\prime}\left(x_{2}^{0}\right)+\beta\right] \\
Y_{2}^{0} & =n_{1} y_{1}+n_{2} y_{2} .
\end{aligned}
$$


Differentiating totally the system (A.14)-(A.16) gives:

$$
\frac{\mathrm{d} n_{2}}{\mathrm{~d} n_{1}}=-\frac{y_{1}}{y_{2}}<0
$$

Notice that for $n_{1}=0$, the maximal population size for city $2\left(\right.$ denoted by $\left.n_{2}^{(4)}\right)$ is $n^{(2)}$ defined in the one city case with $x^{0}=x_{2}^{0}$. For $n_{2}=0$, the maximal population size for city 1 (denoted by $n_{1}^{(4)}$ ) is still $n_{1}^{(3)}$ 


\section{References}

Bear, J., A. Cheng, S. Sorek, D. Ouazar, and I. Herrera (1999): Seawater Intrusion in Coastal Aquifers - Concepts, Methods and Pratices, Theory and Applications of Transport in Porous Media, vol 14. Dordrecht, Kluwer Academic Publishers.

Brozovic, N., D. Sunding, and D. Zilberman (2001): "Why Aquifers are not Bathtubs: Optimal Control of Groundwater Over Space and Time," Presented at the 7th Conference of the International Water and Resource Economics Consortium in Girona, June 3-5, Spain.

Chakravorty, U., E. Hochman, and D. Zilberman (1995): "A Spatial Model of Optimal Water Conveyance," Journal of Environmental Economics and Management, 29, 25-41.

Cummings, R. (1971): "Optimal Exploitation of Groundwater Reserves with Saltwater Intrusion," Water Resources Research, 7(6), 1415-1424.

F.A.0 (1997): "Seawater Intrusion in Coastal Aquifers : Guidelines for Study Monitoring and Control," Water Reports 11, F.A.O, Rome.

Gleick, P. (1993): Water in Crisis: A Guide to the World's Fresh Water Resources. New York, Oxford University Press.

Green, G., and D. Sunding (2000): "Designing Environmental Regulations With Empirical Microparameters: The Case of Seawater Intrusion," Resource and Energy Economics, 22, 63-78.

Koundouri, P. (1997): "Competition Versus Optimal Control in an Aquifer With Seawater Intrusion," mimeo, Cambridge University.

Moreaux, M., And A. Reynaud (2004): "Optimal Joint Management of a Coastal Aquifer and a Substitute Resource," Water Resources Research, Forthcoming. 
Reilly, T., And A. Goodman (1985): "Quantitative Analysis of Saltwater-Freshwater Relationships in Groundwater System-A Historical Perspective," Journal of Hydrology, 80, 125-160. (1988): "Analysis of Saltwater Upconing beneath a Pumping Well," Journal of Hydrology, 89, 169-204.

Swallow, S. (2000): "Depletion of the Environmental Basis for Renewable Resources: the Economics of Interdependent Renewable and Non Renewable Resources," Journal of Environmental Economics and Managment, 19, 281-296.

Tsur, Y., AND A. Zemel (1995): "Uncertainty and Irreversibility in Groundwater Resource Management," Journal of Environmental Economics and Management, 29, 149-161. 
Table 1: Summary of extraction policies.

\begin{tabular}{lllll}
\hline \hline Population & Pumping & Water & Scarcity & Unit \\
Class & Location & Pumping & Rent & Tax \\
\hline 1- Very small & $x_{1}=x_{1}^{0}$ & $y_{1}>y_{2}$ & No & $\mu_{1}^{(1)}$ \\
& $x_{2}=x_{2}^{0}$ & & & $\mu_{2}^{(1)}$ \\
2- Small & $x_{1}=x_{1}^{0}$ & $y_{1}>y_{2}$ & Yes, $\lambda^{(2)}$ & $\lambda^{(2)}+\mu_{1}^{(2)}$ \\
& $x_{2}=x_{2}^{0}$ & & & $\lambda^{(2)}+\mu_{2}^{(2)}$ \\
3- Intermediate & $\left.\left.x_{1} \in\right] x_{1}^{0}, x_{2}^{0}\right]$ & $y_{1} \geq y_{2}$ & No & $\mu_{1}^{(3)}$ \\
& $x_{2}=x_{2}^{0}$ & & & $\mu_{2}^{(3)}$ \\
4- Large & $x_{1}=x_{2}^{0}$ & $y_{1}<y_{2}$ & Yes, $\lambda^{(4)}$ & $\lambda^{(4)}+\mu_{1}^{(4)}$ \\
& $x_{2}=x_{2}^{0}$ & & & $\lambda^{(4)}+\mu_{2}^{(4)}$ \\
5- Very Large & $\left.\left.x_{1} \in\right] x_{2}^{0}, X^{0}\right]$ & $y_{1}<y_{2}$ & No & $\mu_{1}^{(5)}$ \\
& $\left.\left.x_{2} \in\right] x_{2}^{0}, X^{0}\right]$ & & & $\mu_{2}^{(1)}$ \\
\hline \hline
\end{tabular}




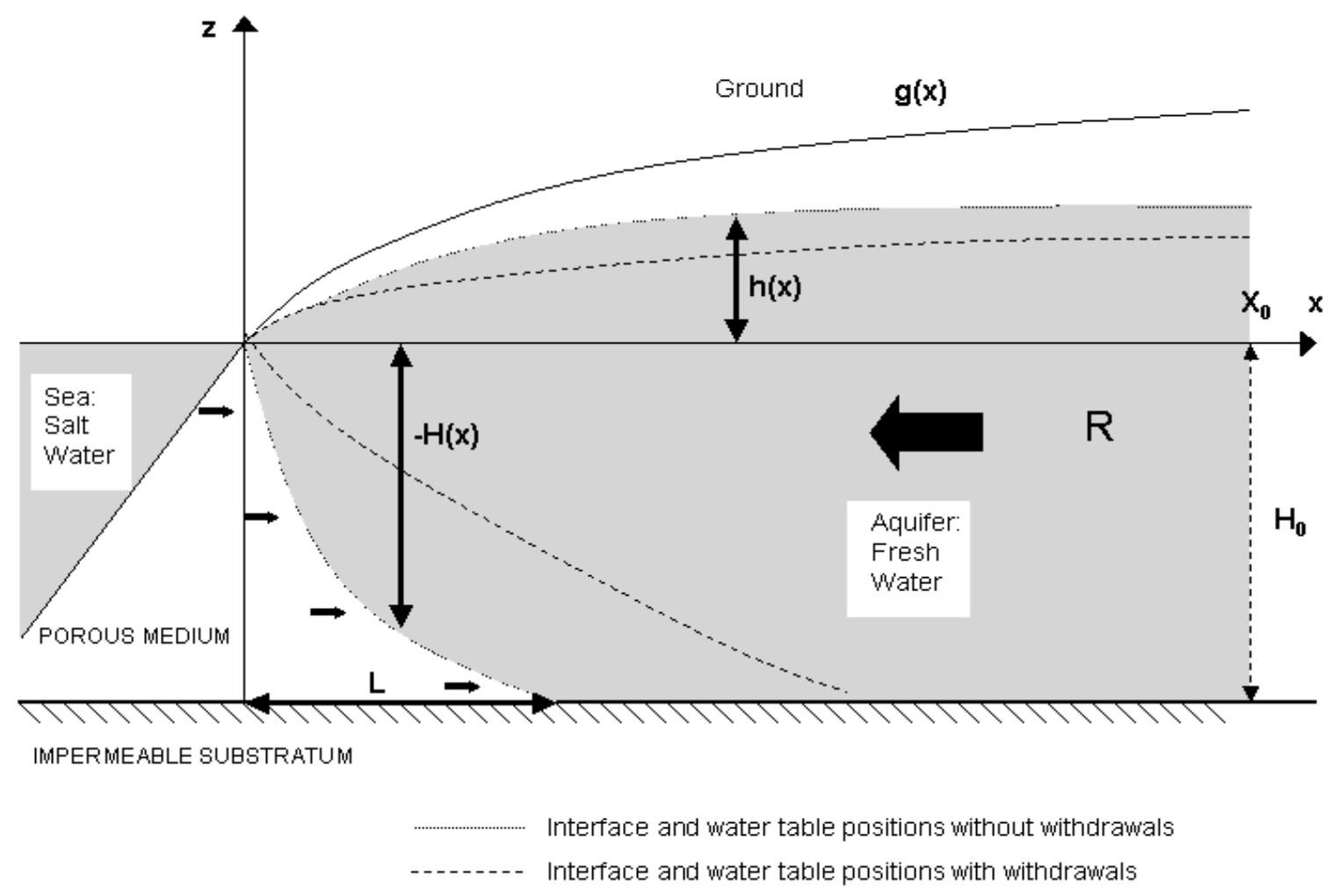

Figure 1: Mathematical modeling of a coastal aquifer under saline conditions. 


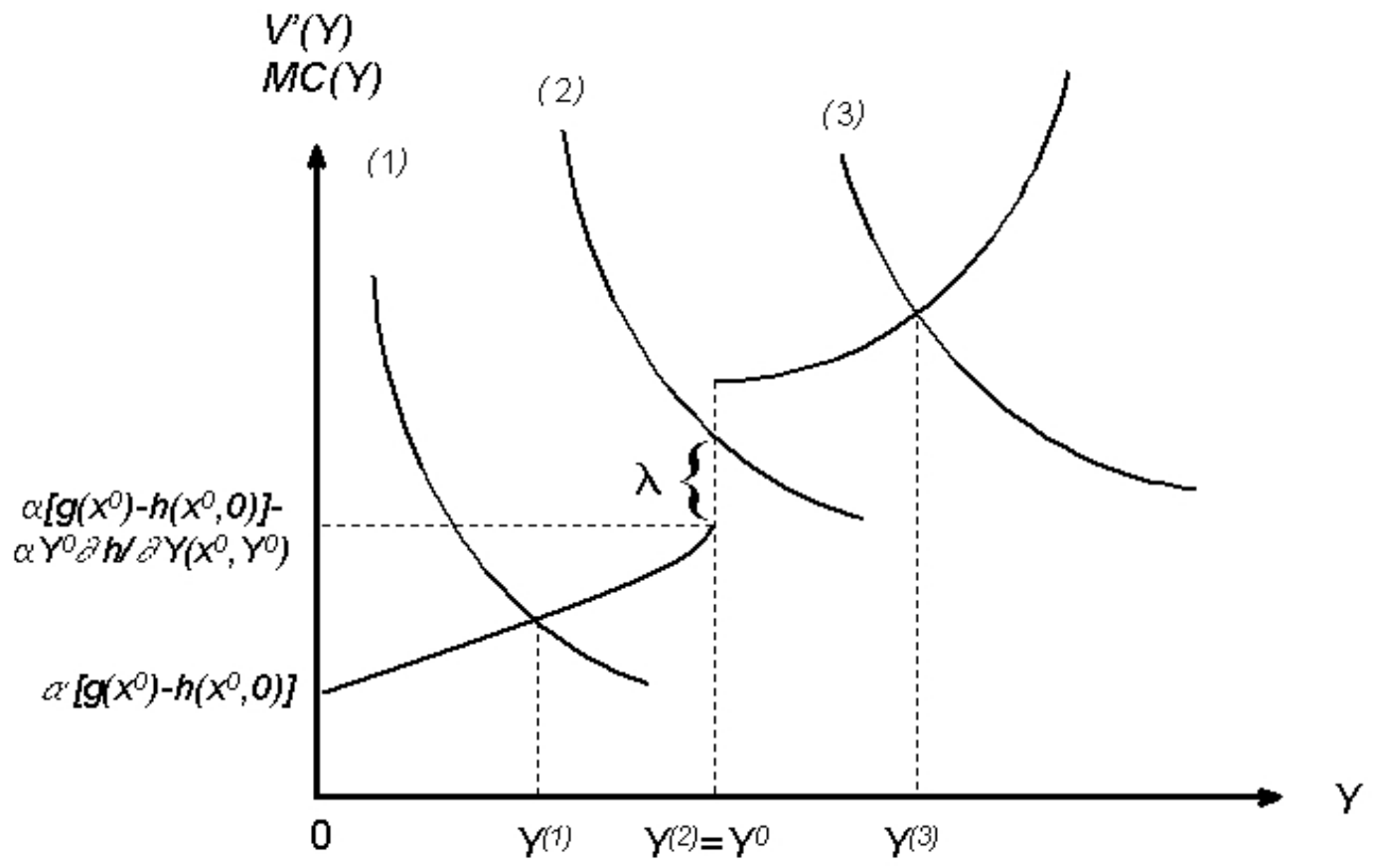

Figure 2: Optimal Exploitation by a single city. 


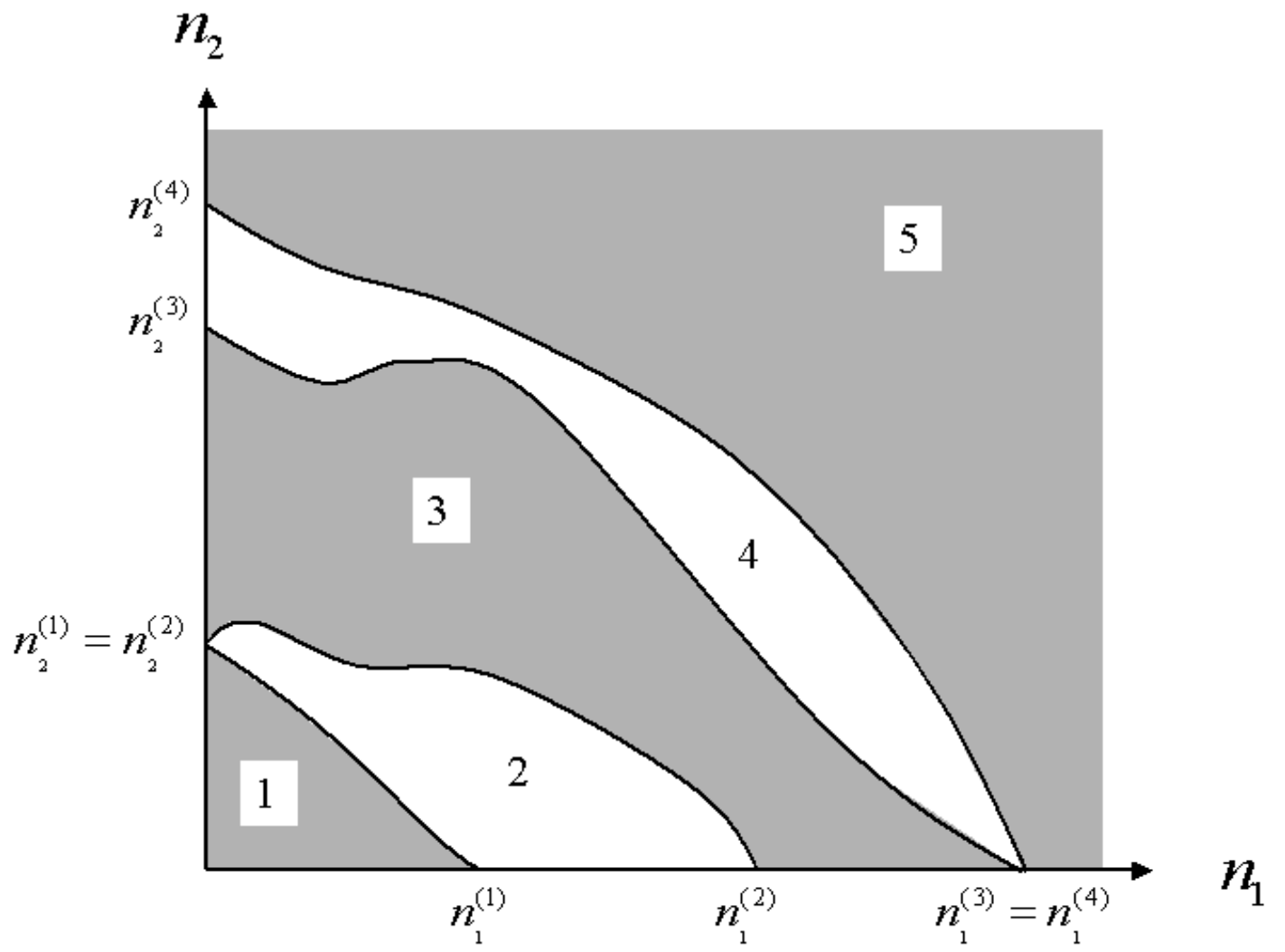

Figure 3: Population space in the two cities case. 